\title{
Corn stubble grazing by steers after mechanical grain harvest 1. Stubble fractions changing through grazing periods
}

\author{
JA Josifovich, OJ Scheneiter \\ Estacion Experimental Agropecuaria Pergamino, INTA, Buenos Aires, Argentine
}

Amounts of corn stubble fractions were evaluated at the start of the grazing period, day 1 (T1), at the middle of the period, 28 days (T2), and at 56 days (T3) in the Argentine corn belt, where 60 day corn stubble grazing is a common practice.

Corn stubble mechanical harvest is composed by stalks $54 \%$, leaves $12 \%$, cobs $21 \%$ and husk $13 \%$ (Vetter, 1973). In our situation these fractions were: stalks $32.5 \%$; husk and leaves $28.7 \%$; cobs $4.8 \%$; grain $10.5 \%$ and spontaneous plants (Cynodon dactylon, Echinocloa sp., Digitaria sp., Lolium $\mathrm{sp}$. and Stellaria sp.) $23.4 \%$. Corn was harvested with a five rows combine, $2.80 \mathrm{~m}$ width.

There were two replications, 1.5 hectare each. The grazing was continuous using steers $245 \mathrm{~kg}$ initial weight, at $3.3 \mathrm{head} / \mathrm{ha}$.

The sampling was done in each period, through five $3.5 \times 0.58 \mathrm{~m}$ samples per replications, across five rows.

Fractions were hand separated and dry matter calculated after 48 hours at $60^{\circ} \mathrm{C}$. Mean and standard deviation for each fraction and sampling periods were calculated.

In the first period (0-28 days) grain, husk, leaves of dry corn plants and green spontaneous plants, which exceeded animal dry matter needs, were selectively grazed. In the second period (28-56 days) the deviation, due to error sampling, and some growth of spontaneous plants, can explain the amount present. As the fractions were exposed to rain and some trampling or natural rooting, as in the case of grain and besides animal consumption, there was a degradation process. During grazing period there were some growth of spontaneous plants, specially annual raygrass. The degradation of corn stubble after 60 days shows that it is not advisable to keep fattening steers grazing the fields for more than 55-60 days after harvest.

\section{Fractions}

$\mathrm{Kg} \mathrm{DM/ha}$

Husk and leaves

Stem

Cobs

Grain

Spontaneous plant

\begin{tabular}{cc} 
Sampling days & - \\
\hline$T 28$ (days 28) & T 56 (day 56) \\
$1498 \pm 497$ & $1439 \pm 230$ \\
$2223 \pm 337$ & $2331 \pm 447$ \\
$630 \pm 499$ & $339 \pm 267$ \\
$5 \pm 12$ & 0 \\
$548 \pm 362$ & $760 \pm 363$
\end{tabular}

